\title{
Factors Influencing High School Students`Preference of either Open and Distance Learning or the Conventional Mode
}

\author{
Thabitha Zinyama ${ }^{1}$, Daniel Ndudzo ${ }^{2}$ \\ ${ }^{1}$ Regional Director, Mashonaland East Region, Zimbabwe Open University, Zimbabwe \\ ${ }^{2}$ Registrar, Zimbabwe Open university, Zimbabwe
}

\begin{abstract}
This study was a survey carried out to establish the factors that influence the decision of high school students to choose between conventional or open and distance learning. The study targeted schools in Marondera urban in which advanced and ordinary level students in their final years responded to questionnaires. The study aimed at tapping the respondents' opinions on how they perceived conventional education visa viz open and distance learning. The questionnaire was administered to 5 out of 12 secondary schools randomly selected in Marondera Urban. All the targeted 100 pupils successfully returned their questionnaires and the collected data were collated and analysed. Results from the study indicate that most high school students are aware of the existence of the modes of learning: the ODL and the conventional mode. The older high school students are more appreciative of the ODL mode than the younger learners. The majority of these high school students shun ODL in favour of the conventional mode of education. Due to lack of more face to face interaction which facilitates more contact time as well as socialisation with peers, the bulk of high school learners would rather opt for the conventional system of education. High school students are computer literate making them potential targets for enrollment in ODL institutions which make extensive use of ICTs. There are poor perceptions of ODL among the learners due to misconceptions about the mode of education. The study therefore recommended that more and vigorous marketing should be undertaken to lure the older high school students who are more appreciative of the ODL mode than the younger learners. There was need for more face to face interaction which facilitates more contact time and socialisation with peers so that the bulk of high school learners would rather opt for the conventional system of education. Block release programmes should be introduced for the young learners to improve on contact time to enhance social interaction and also accord learners more learning time.
\end{abstract}

Key words: Distance education, conventional education, High school students, decision making

\section{Introduction}

Universities are considered as higher education institutions that perform, although in very differing degrees, at least three main activities; teaching, research and community service. In many regional contexts universities are the only providers of knowledge. As a result the number of students enrolled at university has continuously been increasing. To address the excessive demand for tertiary education, distance education has emerged as a tool for widening access to higher education for personnel in education and those that could not be accommodated in the conventional tertiary education system (Spronk, 1999).

From time immemorial the delivery system for higher education has been a classroom setting with a professor giving a lecture and students writing and writing notes. Interaction between the professor and student has been viewed as an essential learning element within this arrangement (O'Malley and McGraw, 1999), often referred to as the "sage on the stage"

Technological improvements such as printing machines, postal services, telephone, radio, television and more recently internet have been a driving force giving rise to new delivery methods and platforms. These new methods used to deliver distance education (DE) are rapidly multiplying in various learning programmes leading some experts to predict that the "residential based models "' in the form of students attending classes at prearranged times and locations, will disappear in the near future (Blustain, Goldstein and Lozier,1999; Drucker, 1997 as cited in O'Malley,1999). Although an expensive option today, video conferencing may create a virtual feeling that we are "back to the classroom". Some forms of DE have progressed in concept and practice from an "anywhere", to an "anytime", to an "any pace" delivery method.

Academic and training communities have been continuously examining, assessing, criticising, hallowing and demonising these new delivery methods. Without doubt DE is of highest relevance and importance to educators, students and all other stakeholders. It is changing the physical face of ie massive buildings) of academic establishments. Students can now learn from the comfort of their homes or offices with no need to commute to campuses. Cutting edge data are easily accessible on compact discs (CDs), portable personal computers (PCs) and have taken the place instantly of obsolete books. Online classrooms and libraries 
are replacing traditional campus facilities. Rather than requiring students to travel to a specific physical classroom or library, the internet has facilitated delivery of almost unlimited learning resources to students.

\section{Background of the study}

Distance education has existed for more than a century' although it has yet to be universally accepted relative to current and well practiced face to face programs provided by traditional brick and mortar institutions. Open and distance learning started as far back as the 1930s in Zimbabwe. Among the early institutions that provided distance and non formal education were a Government Primary Correspondence School, Rapid Results Central Africa Correspondence (CACC), and Zimbabwe Distance Education College (ZDECO). Recently in addition to these non formal education programmes, there is also a number of other institutions which have also registered with the ministries of education and of higher education respectively. These include; The Institute of Personnel Management (IPMZ), International Correspondence School, Distance Education Centre and Open Learning Centre and Centre for Distance Education initially operated by the University of Zimbabwe and later developed into a full scale university known as the Zimbabwe Open University. Almost all tertiary institutions in the country are running parallel programmes by way of block release which is a form of distance learning punctuated by face to face interaction.

The Zimbabwe Open University (ZOU) was set to revolutionise the provision of distance education at tertiary level in Zimbabwe. The clientele for the ZOU is mainly working adults who cannot leave work for full time residential study. They could also be school leavers and youths who are pursuing entrepreneurial activities of one form or another to make ends meet yet still need a university education. The enrolment statistics at the ZOU show that the percentage of high school leavers is insignificant. Hence this study was meant to establish the factors that influence the decision of high school students to choose between Conventional or Open and distance learning in with the view of making ODL the mode of choice for the school leavers.

\section{Statement of the problem}

Open and Distance learning in Zimbabwe has been regarded as an alien system of inculcating knowledge to students. The generality of students is accustomed to the conventional mode of teaching. The Zimbabwe Open University (ZOU) is struggling to attract the school leavers' market despite its success in the provision of education through Open and distance learning. This study therefore seeks to establish the factors that influence the decision of high school students to choose between Conventional or Open and distance learning.

\section{Research Questions}

The study was undertaken to establish the factors that influence the decision of high school graduates to go for either conventional or open and distance learning. The following research questions were answered in an attempt to answer the main research questions:

[1] What are the characteristics of Open and Distance Learning that lure school leavers to enroll through the mode of learning?

[2] What are the characteristics of Conventional education?

[3] What are the perceived flaws of each of the two?

[4] What strategies can be adopted to enroll more school leavers in the ODL programmes?

\section{Purpose of the study}

This study was aimed at establishing why school leavers choose to go for either conventional or open and distance learning. The study was meant to unearth factors that influence the decisions by high school graduates to choose between conventional and open and distance learning and make recommendations on how to make ODL more appealing to high school graduates.

\section{Literature Review}

The term "distance education" has been used to describe the process of providing education where the instructor is distant (geographically separated) from the student (Gallagher and McCormick, 1999) or any instructional arrangement in which the teacher and the learner are geographically separated to an extent that requires communication through media such as print or some other form of technology (Moore and Thompson,1997 as cited in Spooner, Jordan, Algozzine and Spooner ,1999.).

The main features of distance education include physical separation of the instructor and student, the use of technical media, the need for an effective communication system and careful planning, and perhaps the provision of occasional face to face meetings. Implicit in this is the need to provide adequate support for students. More relaxed entry point requirements in ODL, and students having the opportunity of deferring, 
programmes, and even examinations courses up until when they are ready, are some features of ODL that have attracted students to join (Ojo and Olakulehin, 2006).

Due to the geographical separation of the learner and the tutor, ODL has much to do information communication technology which has allowed for learning at a distance. This growth accelerated significantly during the 1990s with the use of computer mediated learning technologies, for example, two way interactive radio, two way audio and web based asynchronous communication; and online or off line internet web based instruction (Phillips and Merisitis, 1999; Ponzurik et., 2000; Sherry, 1996; Wernet et al, 2000; Setaro, 2000). Advancements in increasingly flexible technology have enabled the Web's visual, interactive nature to transform the traditional campus classroom - instructor system into a variety of different and innovative forms of instructional dissemination and to decentralised locations (Hall, 2002; Ponzurik et al., 2000). Some studies have shown that the use of ICTs, however, has provided challenges for ODL as either there are inadequate gadgets offered by the institution or the prospective student is incompetent in the use of these ICTs (Olaofe, 2005; Leary \& Berg; 2007).

The use of ICTs for distance education has had challenges. For example, a study by Myrdal (1994) noted that over $90 \%$ of faculty and students had never used the computer networking capabilities. In a study carried out in California, students had no access to computers or had little knowledge about computers (Fisher and Desberg, 1995). A project in Canada found that even when students had access to computers and knowledge about them generally, students still needed considerable time to master the techniques involved in using e-mail for discussions and communications, and searching and retrieving information from remote sites (Green et al, 1995).

ODL has been hailed for the advantages that it presents. For example, studies have established that distance education students a have greater freedom which entails that the students make a number of important decisions which would normally be made for them (Stewart, 1987). Such flexibility is very difficult to achieve in the conventional universities because their activities and management systems are more rigid and thus restrictive by design. Some studies carried out with students already enrolled have established that flexibility, convenience and logistics have often enticed students to enroll in ODL institutions. To a large extent, students felt that the ODL courses were more convenient than traditional courses (Hiltz; 1998; Richards and Ridley; 1997).

However, despite these advantages and others, ODL poses some challenges. In some studies, it was found out that younger students had difficulties with ODL programmes if offered online but opted to be with a "live person" (Guernsey, 1998), hence these young learners need for face-to-face interaction (Larson, 1967). Furthermore, the effectiveness of distance education for young learners who may be considered less independent and thus may require direct interaction throughout the instructional process is also questionable (Schmidt and Faulkner; 1989). The need for young learners to make new friendships in courses with a face-to-face element which is not possible in the virtual classroom is also a driving force for the young learners to opt for other modes of learning (Larson, 1967; Hiltz, 1998).

The other mode of study that is of importance to this study is the conventional education. Conventional education also known as traditional or back to basics or customary education refers to long established customs found in schools that society has traditionally deemed appropriate. In the eyes of reformers traditional teacher centred methods focused on rote learning and memorisation must be abandoned in favour of student centred and task based- approaches to learning. However, many parents and conservative citizens are concerned with the maintenance of objective educational standards based on testing which favours a more traditional approach. The students are expected to docilely and obediently receive and believe the fixed answers from the teacher. Teachers are the instruments by which knowledge is communicated and standards of behaviour enforced.

Conventional education refers to the long customs that have been established in schools that society deemed appropriate. The main characteristics include face to face interaction between instructor and student, a relatively homogeneous group of largely dependent learners, same location, that is, classroom and relatively "cheat proof".

\subsection{Conventional versus Open and Distance Learning}

In the conventional system, students remain in close and easy contact with the institution, colleagues and lecturers, but in the distance education settings students are often isolated and contact with their university is, at best, infrequent and more often than not takes place at a distance (Guernsey, 1998). However, some distance education researchers (Keegan, 1988; Lewis, 1988) have questioned the need for too much face-to-face student and instructor interaction. These argue that a large amount of interaction as inhibiting the independence of the learner.

Kaufman and Mugridge in their on "Distance Education in Canada", claim that "the lines which hitherto existed between distance and face - to - face education are being blurred or eliminated" as the former becomes more generally accepted and teaching techniques are shared. It appears the boundaries are moving as a result of changes in the concept of conventional, rather than distance education. Moore and Kearsley (2005) 
asserted that ODL may be seen as an approach that is at least complementary and in some circumstances a more appropriate substitute for face to face classroom methods that still dominate most educational systems.

Despite the rapid growth in distance learning, the quality of higher learning via distance education has been called to question (Debe 1996; Harrison 2001 as cited in Peat and Helland, 2002). Walter Perry the first vice chancellor of Open University of the United Kingdom noted the: skepticism garnished with ridicule and hostility" of distance education universities, Young (1994). According to empirical evidence, however, there is no significant difference between learning outcomes that can be attained at traditional institutions versus distance learning (Verduin and Clark 1991)

In some studies, it was found out that younger students had difficulties with ODL programmes if offered online but opted to be with a "live person" (Guernsey, 1998), hence these young learners need for faceto-face interaction (Larson, 1967). Furthermore, the effectiveness of distance education for young learners who may be considered less independent and thus may require direct interaction throughout the instructional process is also questionable (Schmidt and Faulkner; 1989). The need for young learners to make new friendships in courses with a face-to-face element which is not possible in the virtual classroom is also a driving force for the young learners to opt for other modes of learning (Larson, 1967; Hiltz, 1998; Schmidt and Faulkner 1989).

Studies have found little difference in the quality of education received through distance learning versus conventional university classroom settings. Russell (2002) examined numerous studies and similarly reported the "no significant difference" phenomenon Many studies have determined that students taking distance learning courses perform as well as students taking course via traditional methods (Gagne and Shepherd 2001). More often than not, perceptions of the distance learning system in the instructional process is influenced by an individual's beliefs about the advantages of distance education, for himself as a student, as an employer or as an educational planner.

\section{Methodology}

The study was a survey of schools in Marondera urban targeted at advanced and ordinary level students in their final years. The descriptive survey design was adopted because the investigation was concerned with the perceptions of respondents (Leedy, 2001).The study aimed at tapping the respondents' opinions on how they perceived conventional education visa viz open and distance learning. In order to collect data from respondents a questionnaire was used. Five assistant researchers were engaged, one per each school. The questionnaire was administered to 5 out of 12 secondary schools randomly selected in Marondera Urban. A sample of twenty students was then conveniently selected per each school. A pre test was done on 10 pupils and necessary adjustments done to the instrument. Before the questionnaire was administered some explanation was done to the pupils on what ODL and conventional education meant. All the targeted 100 pupils successfully returned their questionnaires and the collected data were collated and analysed.

\section{Presentation and Discussion of Findings}

The respondents consisted of $44(44 \%)$ male and $56(56 \%)$ female high students whose age range was between 16 and 22 years. The 16 to 18 years age range was predominantly composed of "ordinary Level" students in their final year (form 4) and the 19-22 range had advanced Level students in their final year (form 6) in the majority. Out of the $100(100 \%)$ respondents $50(50 \%)$ students were ordinary level while the other 50 (50\%) were Advanced level.

\subsection{Respondents gender distribution}

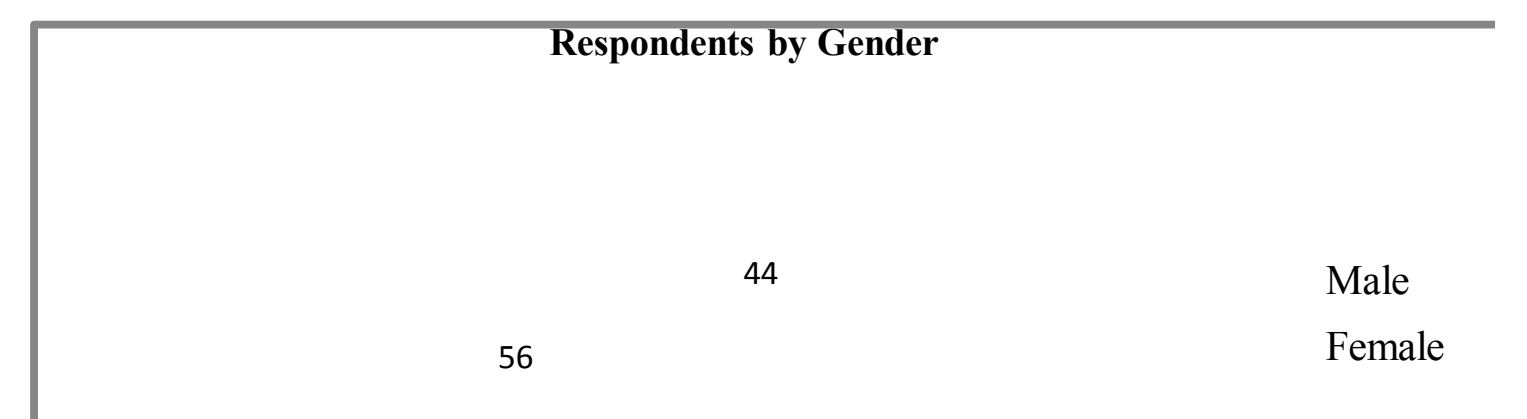

Fig 1: Distribution of respondents by gender 
Fig labove shows that there were 44(44\%) male and 56(56\%) female respondents. The fact that there were more female students in the sample could be explained by the fact that one of the schools selected is a girls ' high school.

\subsection{Respondents age range}

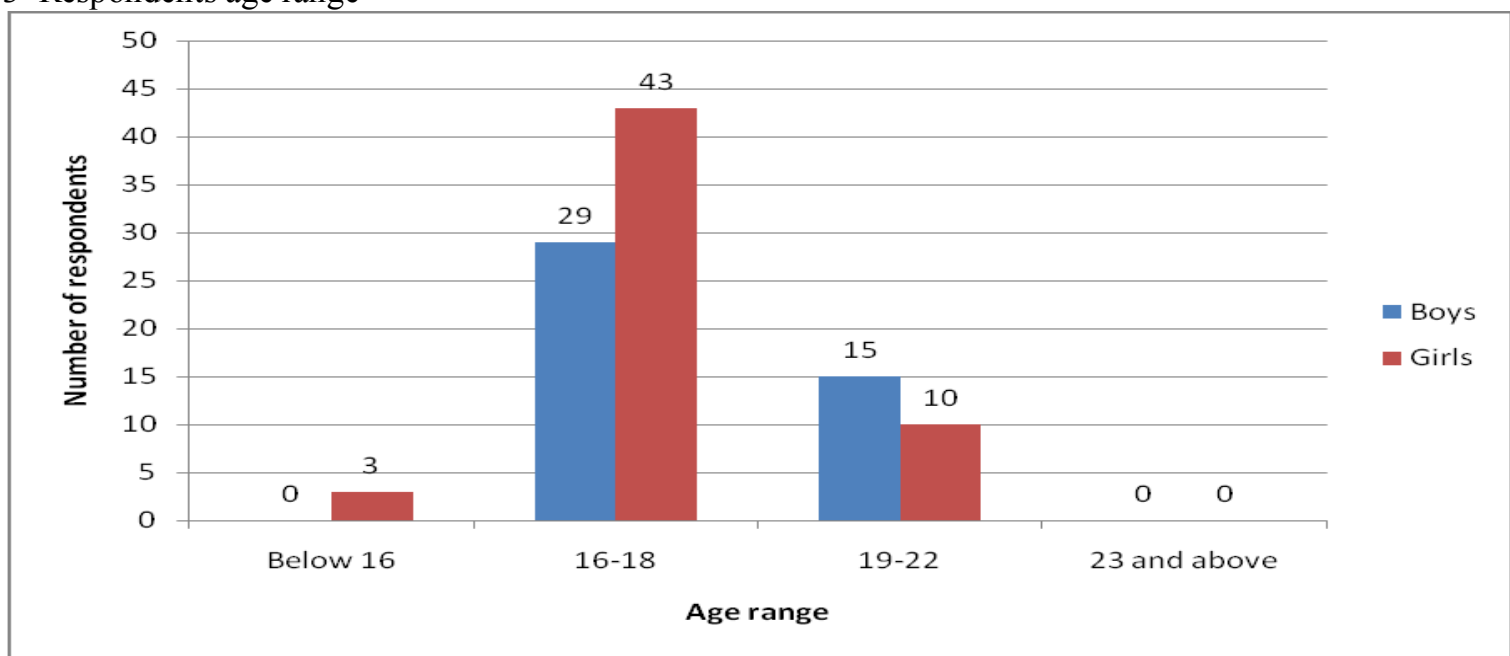

Fig 2: Distribution of respondents by age

Very few, $3(3 \%)$ of the respondents were below 16 years, $72(72 \%)$, the majority were in the age range between 16 and 18 and $25(25 \%)$ were between 19 and 22. This could be age range that traditional ODL has been targeting to enroll for the different programmes.

\subsection{Respondents position in the family}

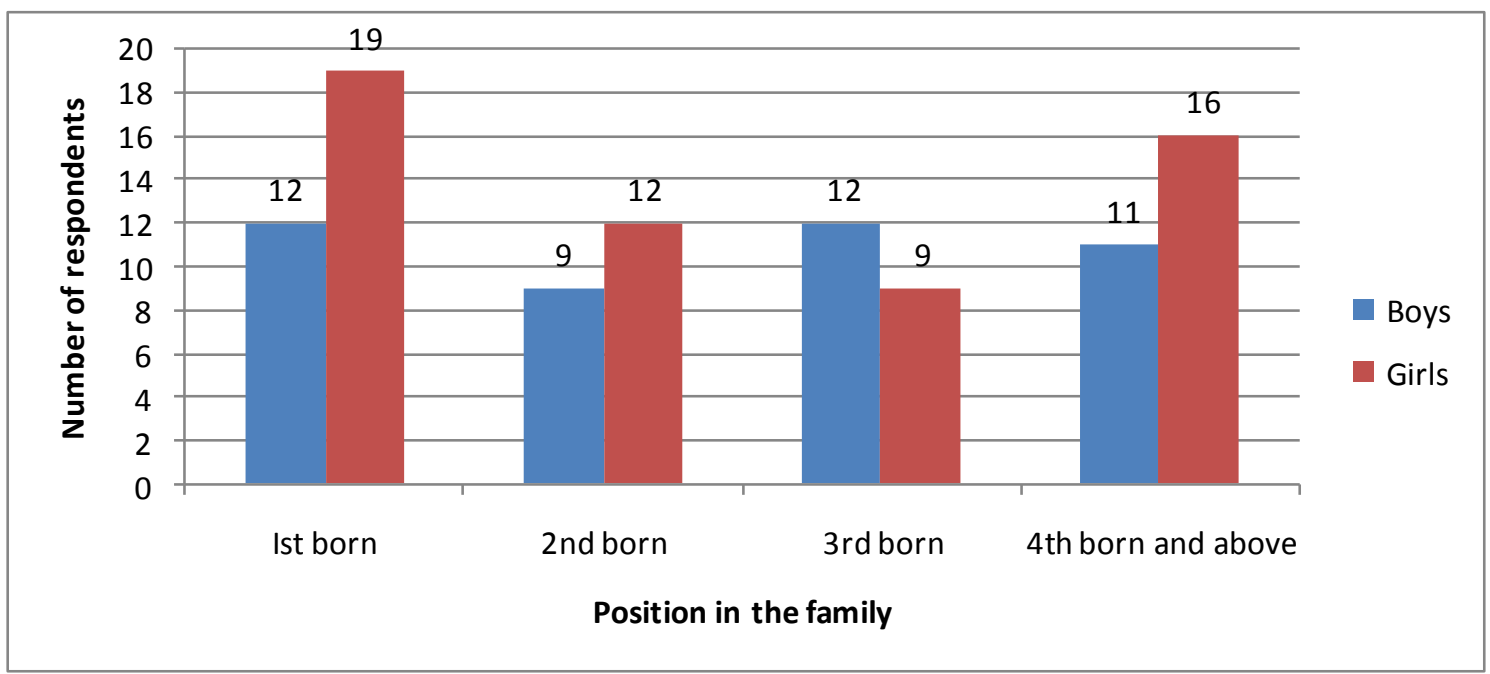

Fig 3: Position of respondents in the family

Figure 3 shows that the majority of the respondents, 31 (31\%) were first born children in their families while the second and third born children accounted for the least percentages at $21(21 \%)$. With the view that parents tend to monitor and influence more first born children, their choice of careers as well as mode of education could also be influenced to a great extent by the parents. These first born children also tend to be role models of the rest of the children. However, from another perspective, it can be noted that while the first born children are appreciative of their role to assist their siblings, the most important option for study would be ODL as they work and earn and assist with the family's day to day needs. 


\subsection{Respondents level of study}

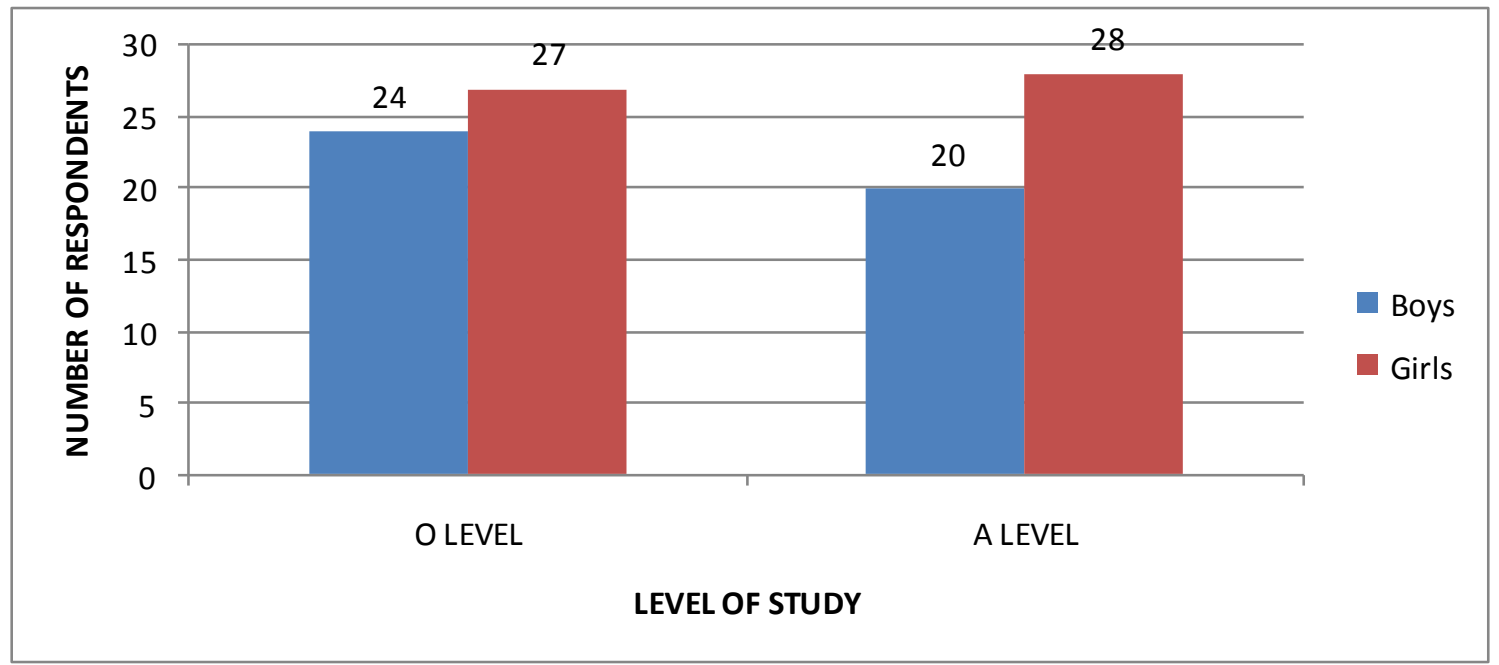

Fig 4: Distribution of respondents by level of study

Fifty $(50 \%)$ of the respondents were ordinary level while the other $50(50 \%)$ were advanced level. These were the most appropriate targets for ODL.

\subsection{Parents input on respondents choice of university}

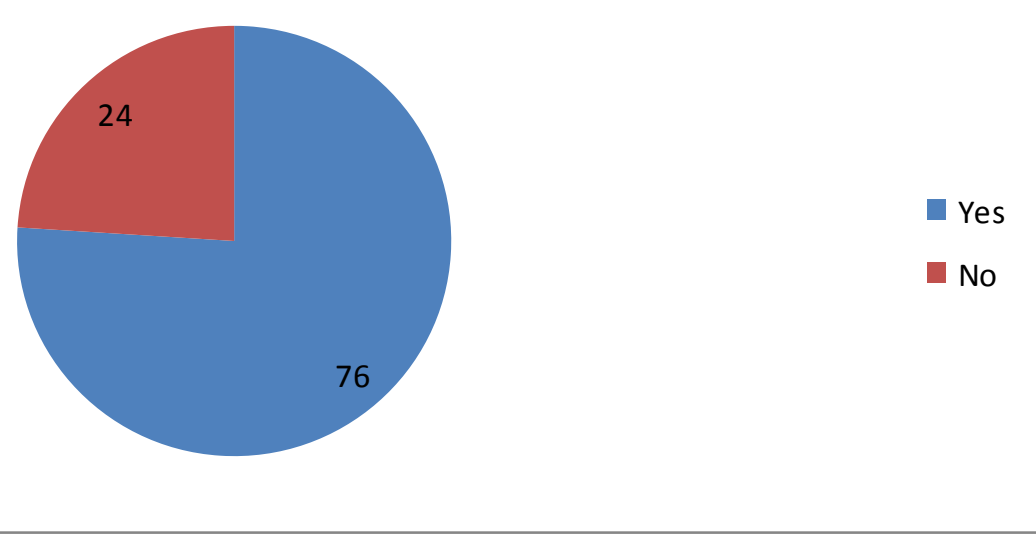

Fig 5: Distribution of responses on parents` input in the choice of university

Figure 5 shows that $24(24 \%)$ of the respondents pointed out that their parents had an input into the choice of university they chose while $76(76 \%)$ said parents did not. This goes to show that when required to make a choice, the majority of students were at liberty to choose a university education mode of their own. This then could be an opportunity to sell the ODL delivery mode to those students who could decide on their own either to go for ODL or conventional.

\subsection{Respondents Understanding of ODL and Conventional education}

Asked what they understood by either conventional or open and distance learning, the students had various interpretations of the two modes. For the ODL mode the most prevalent responses were that in ODL one will be learning whilst at home and students learn on part time. Some stated that it was for those without sufficient money to stay on campus while others said it was for those who quickly understand without much lecture. Other views were that it entailed doing study while independent and going to work. There were some who pointed out that ODL was where people of various ages will be mixed and having tutorials on weekends and using modules. Some said information was not delivered face to face and that ODL was learning through researches and books and internet and being helped by tutorials in the absence of lecturers but on your own using modules and at your place. Interestingly also, responses indicated that ODL was for slow learners.

The above responses show clearly that the students understood that there is quasi separation of the learner and the teacher in time and space (Keegan 1996). They pointed out that it is a method where students are independent learners and use some form of media either the module or internet. Students get an opportunity to engage in other activities while learning, for example, working. It is acknowledged that ODL is more accessible 
and cheaper. Some believed that it was designed for the bright students who did not need much lecturing while others on the other hand thought it was for slow learners who needed more time.

On their understanding of the conventional mode a diversity of views was obtained. The majority understood the mode to be one in which one will be learning whilst staying at university, thus one sticks to learning full time without doing both working and learning. Respondents indicated that there was more time to study because there was no interruption. There were lectures as opposed to tutorials. While some stated that the mode was meant for bright learners, others stated there was limited access to conventional systems and at the same time it was not easy to pass conventional programmes.

It is clear that respondents understood that in the conventional mode, there is more face to face interaction with the teacher, a lecture method is used and there is closer supervision by the teacher. One concentrates on learning and may not be able to engage in other activities like working. Access is restricted unlike in ODL where there was open access and flexibility as shown by the entrance points in ODL where five ordinary level passes were the entrance grade.

\subsection{Respondents preferred mode of study}

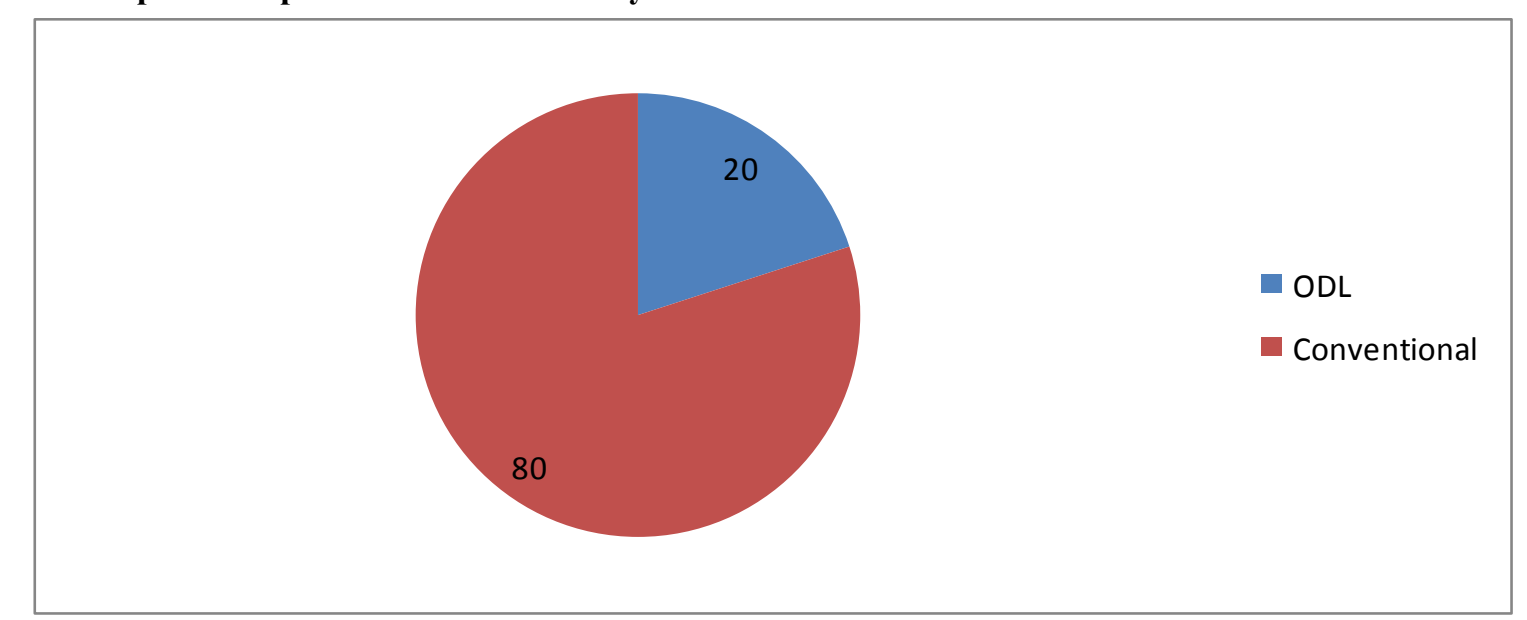

Fig 6: Respondents` preferred mode of study

From figure 6, it can be seen that the majority of the respondents $80(80 \%)$, opted for the conventional system whereas only $20(20 \%)$ went for the ODL mode. When asked to justify the choice of university, the majority of those who had opted for ODL justified their choice of mode of learning by remarking that ODL was cheap. It also provided the best learning environment and allowed one to work while they earn. There were no problems in finding accommodation and one avoided peer pressure and there was support from the family on a daily basis. Popular also was the view that one learnt from people of different ages. Most striking from these findings is the fact that these responses wee form the respondents from the 19-22 age range. The majority of these were also the first and second born children in their families. The respondents might have felt the need to stay at home, work and earn money to assist the family.

Those who had opted for the conventional mode justify their choice of mode of learning by remarking that there was more time to concentrate on studies as there were fewer disturbances. Also in the majority was the view one studied on the campus and there was no waste of time moving from one place to the other. This is so given that some learners are not gifted and thus find learning material difficult to handle and would therefore, need more time. Schmidt and Faulkner (1989) likewise found out that less independent young learners may require direct interaction throughout the instructional process and therefore found the effectiveness of ODL questionable

The commonest response, from $60(60 \%)$ respondents, was that one socialised with peers. This is in line with the findings by Larson (1967) and Hiltz (1998) who established the need by young learners to make new friendships in face-to-face programmes as a driving force for the young learners to opt for the conventional modes of learning

\subsection{Factors that influence choice of mode of learning}

Respondents were asked to enumerate the factors that influence choice of mode of learning. Prevalent among those factors enumerated among the respondents were the following:

- Cost which takes into account accommodation, fees and transport.

- Effectiveness and availability of learning facilities.

- Stability of the economy. 
- Family at home.

- Flexibility

- Availability of time.

- Marital status

Respondents were also asked to state the factors that would entice respondents to enroll through ODL. The responses included the following which were more popular:

- Cost

- Opportunity to learn while you earn

- University facilities

- Availability of transport to the learning centres

- Learning away from peer pressure

The study also sought to establish the factors that would dissuade respondents from enrolling through ODL. The following were more popular among the respondents:

- Lack of socialisation

- There is no face to face interaction

- Conventional provides for close interaction with lecturers

- There is less monitoring from the tutor

- Lack of consultation

- Balancing work and study can be difficulty

- The conventional mode provides quality education due to more contact time

- Learning with old people is weird to our generation

- People say degree programmes through ODL are inferior to those offered in conventional universities

- ODL education is expensive

These findings replicate previous studies which have established that some students need face to face interaction (Larson, 1967; Guernsey, 1998). However, a contradiction with findings exists where concerns about the effectiveness of distance education for learners who may be considered less independent and thus may require direct interaction throughout the whole instructional process (Schmidt and Faulkner; 1989). This is so because some of the respondents indicated that degree programmes through ODL were inferior to those offered in conventional universities Hiltz (1998) reported that students are often isolated and contact with their university is, at best, infrequent and more than not takes place at a distance. However, other distance researchers (Keegan, 1998; Lewis, 1998) have questioned the need for too much face to face student and instructor interaction. These argue that a large amount of interaction is inhibiting to the independence of the learner.

\subsection{Respondents' judgment of the quality of ODL viz a viz conventional education}

The majority of the respondents considered ODL to be of poor quality as compared with conventional education. On the other hand, a minority stated that ODL was of very high quality. One remarked that if the institution had university status, it means it has quality education at the same giving you the opportunity and time to do some other activities like jobs. The findings are in line with previous studies that have indicated that the quality of higher learning via distance education is questionable (Debe 1996; Harrison 2001 as cited in Peat and Helland, 2002). The study also replicates Walter Perry's remarks that there is skepticism garnished with ridicule and hostility to distance education universities. However, in contrast, some studies have established that there is no significant difference between learning outcomes that can be attained at traditional institutions versus distance learning (Russell, 2002; Verduin and Clark, 1991).

1.11 Respondents` views on whether ODL flexibility and convenience attracted them as school leavers

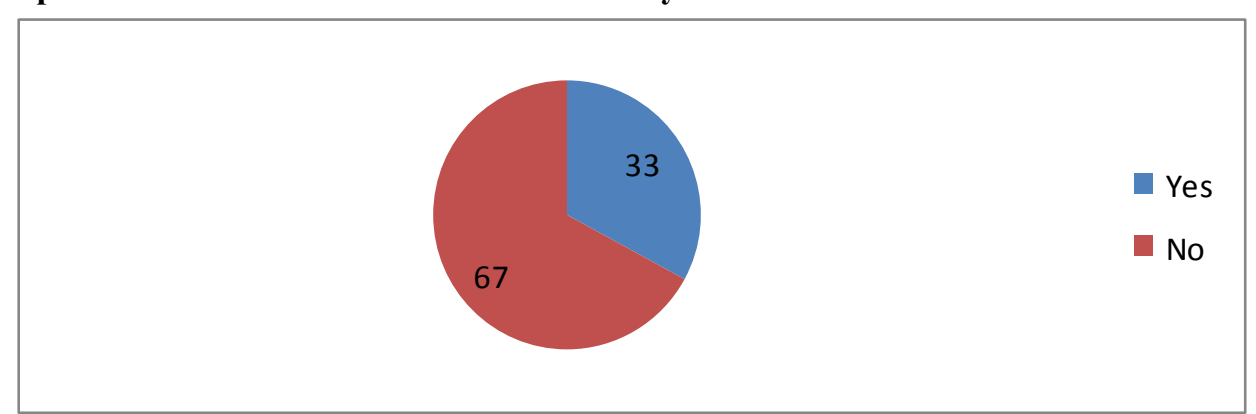

Fig 7: Respondents` views on whether ODL flexibility and convenience attracted them as school leavers 
Figure 7 shows that the majority 67 (67\%) of the respondents said no when asked whether ODL flexibility and convenience attracted them as school leavers. A minority of 33(33\%) answered yes to the same question. The most popular responses for those who indicated yes were that there was more time to stay with relatives, it was quite reasonable to work and get educated at the same time, one learnt at his/her own pace and that with ODL they got to have my privacy and work at the same time. Those who indicated no as their responses indicated that being closer to lecturers was better, there was no socialisation in ODL, there was less time for study in ODL and it was learning method for the old people. Most popular also was the view that the young learners wanted to experience life away from home and some still needed guidance in school work and besides they were not fully grown.

The results of this study contradict those by Hiltz (1998), Richards and Ridley (1997). Their studies established that flexibility, convenience and logistics enticed the majority of students to enroll in ODL institutions. According to these studies, to a large extent, students felt that the ODL courses were more convenient than traditional courses.

\subsection{Level of ICT competency among respondents}

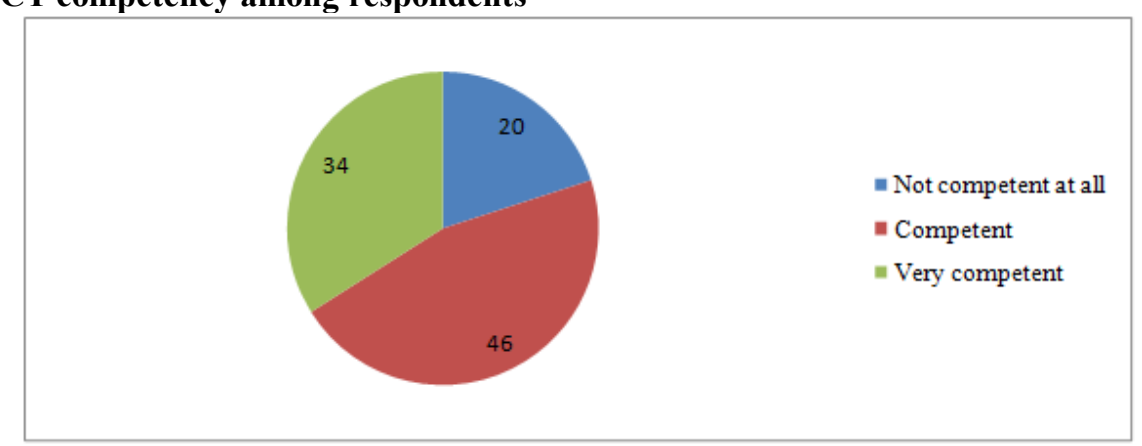

Figu 8: Level of ICT competency among respondents

Figure 8 shows that a minority of $20(20 \%)$ respondents indicated that they were not competent at all in the use of ICTs. Thirty-four (34\%) stated that they were competent whereas the majority $46(46 \%)$ said they were very competent in the use of ICTs. This is consistent with the modern trend whereby the young generation as opposed to the elder generation is digital wise. This could be the right generation for ODL where there is intensive use and adoption of modern technology among which are computers and cellular phones. However, by contrast, some studies have shown that due to incompetence in ICTs, some learners and teachers have shunned ODL where there was intensive use of the same. In line with is for example, a study by Myrdal (1994) noted that over $90 \%$ of faculty and students had never used the computer networking capabilities, in California, students had no access to computers or had little knowledge about computers (Fisher and Desberg, 1995).

1.13 Respondents` views on whether or not there is socialisation from a wide socio-cultural background once enrolled through ODL

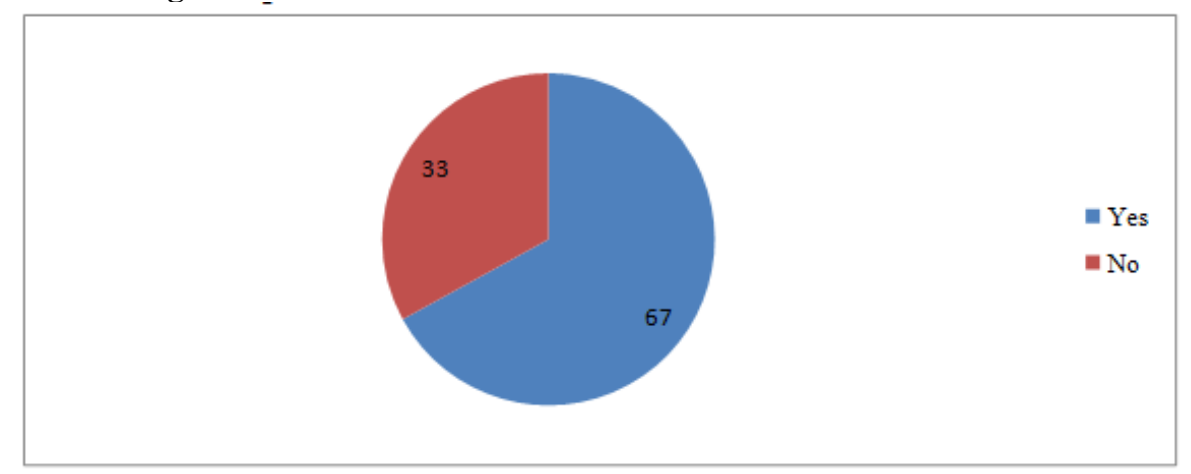

Fig 9: Respondents` views on whether or not there is socialisation from a wide socio-cultural background once enrolled through ODL

1.14Respondents` views on what could be done to enhance the acceptance of ODL among school leavers in Zimbabwe

A good number of strategies were put forward by the respondents. The most popular strategies that were put forward by the respondents were that there was need to establish more ODL centres and the respondents advocated for more tutorials and most of these should be on-line lessons. The response is not surprising as the majority of the respondents is ICT competent, hence would find no challenges with on-line learning. Some said there was need to parade role models in ODL to remove the negative perceptions held by 
people on ODL programmes. There was need for more awareness on ODL programmes to the school leavers. A good number indicated that there was need to establish permanent premises and where lessons were to be held, there was need for separate classes for school leavers and the working class. The majority 83(83\%) muted the need to allow for socialisation through camping days and block release programmes. This is in line with the assertions by Valenta, Therriault, Dieter and Mrtek (2001) that the success of long-distance learning hinges on its capacity to simulate a dynamic campus classroom. This is so given that the young learners are not willing to sacrifice that shared experience merely for the convenience of studying at home (Ojo and Olakulehjin; 2006 Keegan, 1988; Lewis, 1988). Some 53(53\%) thought there was need to broadcast on radio, television and the print media so that parents and children understood the concept of ODL. The strategy could be effective in perception change since the majority of people have access to radio and television.

\section{Conclusions}

From the above findings, it can be therefore, concluded that:

- Most high school students are aware of the existence of the modes of learning: the ODL and the conventional mode.

- The older high school students are more appreciative of the ODL mode than the younger learners.

- The majority of these high school students shun ODL in favour of the conventional mode of education.

- Due to lack of more face to face interaction which facilitates more contact time as well as socialisation with peers, the bulk of high school learners would rather opt for the conventional system of education.

- High school students are computer literate making them potential targets for enrollment in ODL institutions which make extensive use of ICTs.

- There are poor perceptions of ODL among the learners due to misconceptions about the mode of education.

\section{Recommendations}

From the above conclusions, it can be therefore, recommended that:

- More and vigorous marketing should be undertaken to lure the older high school students who are more appreciative of the ODL mode than the younger learners.

- There is need for more face to face interaction which facilitates more contact time and socialisation with peers so that the bulk of high school learners would rather opt for the conventional system of education.

- Block release programmes should be introduced for the young learners to improve on contact time to enhance social interaction and also accord learners more learning time.

- The university should make attempts to improve on the ICTs for instructional purposes so that the high school students who are computer literate can be persuaded to enroll through ODL.

- There is also need for the university to seek means for changing stakeholder perceptions on the quality ODL programmes.

\section{References}

[1]. Spronk, B. (1999). Ghana distance education development project - UPCD tier 2 mid-term evaluation. England: International Extension College (IEC), 33.

[2]. Phipps, R., and Merisotis, J. (1999). What's the Difference? A review of Contemporary Research on the Effectiveness of Distance education in Higher Education. The institute for Higher Education policy.

\section{Journal Papers}

[3]. O’Malley, J., \& McCraw, H. (1999). Students perceptions of distance learning and the traditional classroom. Journal of Distance learning Administration, II(IV.)

[4]. Gallagher, P. A., \& McCormick, K. (1999). Student satisfaction with two-way interactive distance learning for delivery of early childhood special education coursework. Journal of Special Education Technology, 14, 32-47.

[5]. Spooner, F., Jordan, L., Algozzine, B., and Spooner, M. (1999). Student ratings of instruction in distance education and on-campus classes. The Journal of Educational Research 92(3), 132 - 140.

[6]. Ojo, D, A. and Olakulehjin, F. K.(2006). "Attitudes and Perceptions of Students to Open and Learning in Nigeria". International Review of Research in Open and Distance Learning Volume 7, Number 1. National Open University of Nigeria.

[7]. Ponzurick, T., Russo France, K., and Logar, C. (2000). Delivering Graduate Marketing Education: An analysis of face-to-face versus distance education. Journal of Marketing Education 22(3), 180 - 187.

[8]. Sherry, L. (1996). Issues in Distance education. International Journal of Educational Telecommunications, 1 (4), 337 - 365.

[9]. Leary, J. \& Berge, Z. (2007). Successful distance education programmes in sub-Saharan Africa, Turkish online Journal of distance education-TOJDE, 8(2), 136-145.

[10]. Hiltz, S.R. (1998). Impacts of college-level courses via asynchronous learning networks: some preliminary results. Journal of Asynchronous Learning. http://www.thejournal.com/magazine/vault/A2596.cfm.

[11]. Schmidt, B. J., \& Faulkner, S. L. (1989). Staff development through distance education. Journal of Staff Development, 10(4). 
[12]. Hiltz, S. R. (1998). Impacts of college-level courses via asynchronous learning networks: some preliminary results. Journal of Asynchronous Learning

[13]. Keegan, D. (1988). Problems in defining the field of distance education. The American Journal of Distance Education, 2 (2), 4-11.

[14]. Gagne, M., and Shepherd, M. (2001). Distance learning in accounting. T.H.E. Journal, 28 (9), 58-65.

[15]. Guernsey, L. (1998). Distance education for the not-so-distant. Chronicle of Higher Education.

[16]. Richards C. N., Ridley D. R., Factors affecting college students' persistence in on-line computer-managed instruction. College Student Journal [serial online]. December 1997:490-5. Available from: WilsonSelect through OCLC FirstSearch.

[17]. Hall, B. (2002). FAQs About E-Learning. Brandon-Hall.com. Retrieved from:http://www.brandon-hall.com/

\section{Proceedings Papers:}

[18]. Olaofe, I.A. (2005). Nigerian educational emancipation: roadmap from crisis to resurgence. Faculty of Education Seminar Series, No. 1. Ahmadu Bello University, Zaria.

[19]. Myrdal, S. (1994). Teacher education on line: What gets lost in electronic communication; Educational measurement: Issues and practice.

[20]. Barnes, J. M. (1995). Embodiment, Hermeneutic, Alterity and Background relations on the internet. A paper presented at the annual meeting of the American Educational Research Association. San Fransisco CA.

[21]. Fisher, F. \& Desberg, P. (1995). The efficacy of adding e-mail to a distance learning Class, Paper presented at the Annual Meeting of the American Educational Research Association, San Fransisco, CA.

[22]. Greene, B.I., Robbins, J., Riley, J., \& Barnes, J. (1995). Instructional use of the Internet: Role of teacher education. Technology and Teacher Education Annual(pp. 631-634). Charlottesville, VA: Association for the Advancement of Computing in Education.

[23]. Lewis, R. J. (1988). Instructional applications of information technologies: A summary of higher education in the west. In Western Interstate Conference for Distance Education, . Boulder, CO.

[24]. A summary of higher education in the west. In Western Interstate Conference for Distance Education, . Boulder, CO.

[25]. Young, M. (1994). Prospects for Open Learning. Lecture held at the Open University at Churchill College in Cambridge England on April 151994.

[26]. Russell, T.L. (2002). The no significant difference phenomenon. Raleigh: North Carolina State University.

[27]. Peat J., and Helland, K. (2002). Perceptions of Distance Learning and the Effects on Selection Decisions. Retrieved from: http://bus.utk.edu/iopsyc/pdf/Perceptions-of-Distance-Education-siop2003.pdf

[28]. Setaro, J. (2000). How E-Learning Can Increase ROI for Training. learning.thinq.com website. Retrieved from: http://www.learning.thinq.com/

\section{Thesis}

[29]. Wernet, S., Olliges, R., and Delicath, T. (2000). Post-course evaluations of WebCT (Web course tools) classes by social work students. Research on Social Work Practice, 10(4), $487-503$.

\section{Books}

[30]. Keegan, D. (1996). Foundations of Distance Education (3rd ed). London: Routledge.

[31]. Moore, M. \& Kearsley, G. (2005) Distance Education: A Systems View (2nd Edition). New York: Thomson/Wadsworth.

[32]. Verduin, John R., \& Clark, T. A. (1991). Distance education: The foundations of effective practice. San Francisco, CA: JosseyBass.

[33]. Leedy, P.D. \& Ormrod, J.E. 2001, Practical Research: Planning and Design, $7^{\text {th }}$ edn, Merrill Prentice Hall, Upper Saddle River, New Jersey.

[34]. Keegan, D. (1996). Foundations of distance education ( $3^{\text {rd }}$ ed.). London: Routledge. 